\title{
MENCIPTAKAN UMKM UNGGUL DAN TERSTANDARRISASI DALAM MEMASUKI PASAR GLOBAL
}

\author{
${ }^{1 *}$ Mariana Rachmawati, ${ }^{2}$ Annisa Lisdayanti, ${ }^{3}$ Ni Putu Nurwita Pratami \\ Wijaya, ${ }^{4}$ Gallang Perdana Dalimunthe, ${ }^{5}$ Dinda Kayani Putri Bestari, \\ ${ }^{6}$ Fansuri Munawar, ${ }^{7}$ Iwan Ridwansyah \\ Universitas Widyatama \\ Email : ${ }^{1}$ mariana.rachmawati@widyatama.ac.id
}

Manuskrip: Sept-2020; Ditinjau: Okt-2020; Diterima: Okt-2020;

Online: Jan-2021; Diterbitkan: Jan-2021

\begin{abstract}
ABSTRAK
Usaha Mikro Kecil Menengah (UMKM) saat ini bisa dibilang sebagai motor penggerak roda perekonomian bangsa. Pengangguran banyak diserap, meski tidak terlihat tapi itu nyata. Untuk melebarkan sayap usaha, UMKM perlu dorongan supaya bisa terus berkembang sehingga kestabilan ekonomi negeri tetap terjaga. Hal itu tentu saja perlu perhatian dari pihak terkait sehingga umkm tidak lagij alan di tempat melainkan melaju pesat. Revolusi industri 4.0 yang cenderung memasarkan memasarkan produknya di pasar ekspor atau pasar global, oleh karna itu para pengusaha UMKM ini perlu diberi arahan dan informasi bagaimana memasuki pasar ekspor-mister exporter dengan sasaran kegiatan memberikan Edukasi dan Pembinaan Prosedur dan Standarisasi UMKM dalam Memasuki Pasar Global seperti: Bagaimana mengembangkan bisnis UMKM agar siap bersaing dengan pasar global,bagaimana tahapan prosedur ekspor dan Standarisasi produk UMKM ini dapat memasuki Pasar Global, Memahami dan menganalisa karakteristik budaya untuk penetrasi pasar Internasional dengan memahami bagaimana karakteristik dari masing - masing negara yang berbeda. Tujuan Kegiatan Menciptakan UMKM Unggul dalam Menghadapi Pasar Global. Metode pelaksanaan PKM dengan Pemaparan Materi, Forum diskusi dan Tanya Jawab dengan virtual conference menggunakan Zoom Meeting berkaitan dengan pandemic corona. Peserta kegiatan ini adalah para Pengusaha UMKM di Wilayah Kota Bandung.
\end{abstract}

Kata Kunci: Perkembangan Bisnis Pasar Global, Prosedur Ekspor, Standarisasi, Produk Ekspor, Analisa Karakteristik Budaya Suatu Negara.

\section{PENDAHULUAN}

Usaha Mikro Keci Menengah (UMKM) memegang peranan yang sangat penting bagi perekonomian Indonesia, termasuk di dalamnya adalah perekonomian Kota Tegal. Data dari Badan Pusat Statistik (BPS) menunjukkan bahwa persentase jumlah Usaha Mikro Kecil Menengah (UMKM) dibandingkan dengan total 
perusahaan pada tahun 2010 adalah sebanyak sebesar 99 persen, sedangkan sisanya adalah perusahaan besar. Pada tahun yang sama jumlah tenaga kerja yang terserap pada sector ini mencapai sebesar 97 persendari total angkatan kerja yang bekerja. Sumbangan pada Produk Domestik Bruto (PDB) pada perekonomian Indonesia mencapai 56 persendari total Produk Domestik Bruto (PDB), dengan nilai penciptaan devisa lebih dari 20 persen.

\section{Strategi dalam Mengembangkan Bisnis UMKM dalam Memasuki Persaingan Pasar Global}

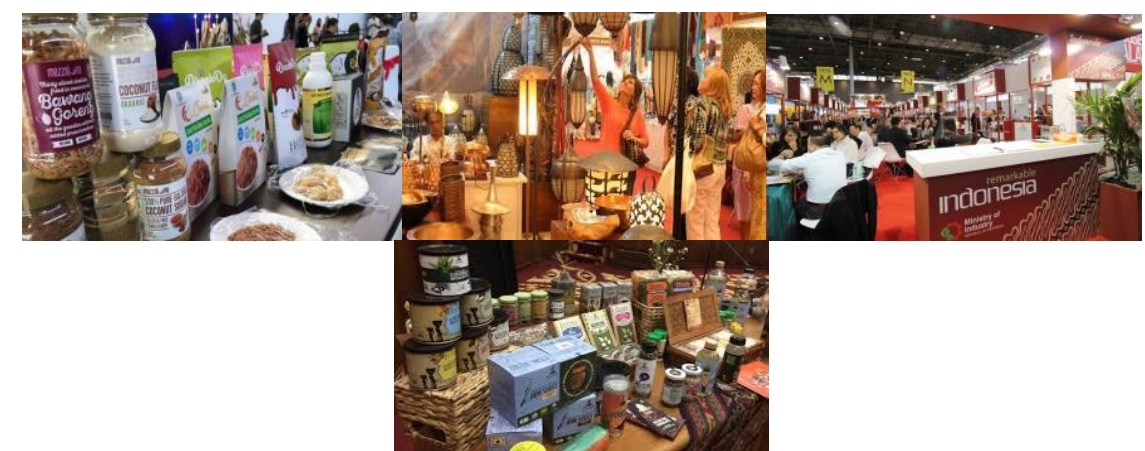

Gambar 1. Hasil Pengembangan Bisnis UMKM

Pelaku usaha mikro, kecil, dan menengah (UMKM) harus memiliki hasrat untuk berkompetisi di pasar internasional. Apalagi, perlu Anda ketahui, deretan perusahaan dengan reputasi besar saat ini. Perusahaan-perusahaan besar yang bermula dari usaha kecil di garasi itu memiliki reputasi yang tak bisa dianggap sebelah mata. Setiap pelaku bisnis UMKM memiliki potensi untuk bisa membesarkan usahanya seperti UMKM .

Hanya saja, kesuksesan itu tak bisa didapatkan secara instan, harus disertai dengan kerja keras dan strategi jitu. Nah, terkait strategi jitu agar bisa bersaing di pasar internasional, Anda bisa menerapkan 5 tips mengembangkan bisnis UMKM berikut:

\section{- Segmentasi pasar}

Tips mengembangkan bisnis UMKM agar menjadi perusahaan besar yang pertama adalah menetapkan segmentasi pasar. Anda jangan mengharapkan untuk menjual produk atau menawarkan jasa pada semua orang yang berada di sekitar tempat usaha. Segmentasi pasar seperti ini menjadi strategi yang dilakukan oleh setiap perusahaan, utamanya perusahaan besar. Anda bisa saja menawarkan produk yang sama dengan pelaku UMKM lain..

- Manfaatkan kerjasama

Persaingan dengan perusahaan besar menjadi hal yang sering dikeluhkan oleh para pelaku UMKM. Namun, hal tersebut tak menjadi alasan para pelaku UMKM tidak bisa mengembangkan usahanya. Sebagai gantinya, Anda bisa melakukan kerjasama pada bidang-bidang yang belum dimiliki.Sebagai contoh, Anda merupakan pelaku UMKM yang memproduksi 
barang-barang kebutuhan rumah tangga. Di sisi lain, Anda kesulitan dalam melakukan distribusi ataupun pemasaran. Pada kondisi ini, Anda bisa mengajak kerjasama perusahaan lain yang bisa membantu Anda dalam distribusi ataupun pemasaran barang. Biar kerjasama yang dilakukan tak terlalu memberatkan, Anda bisa saja menerapkan sistem komisi.

- Otomasi,

Tips mengembangkan bisnis UMKM selanjutnya adalah dengan memperhatikan tenaga yang direkrut. Jangan terlalu banyak merekrut tenaga kerja, karena bakal memakan porsi pengeluaran yang besar. Kalaupun memang harus merekrut orang, pastikan perekrutan itu dilakukan secara tepat dan sangat dibutuhkan. Orang yang dipilih juga bukan orang sembarangan, melainkan tenaga dengan kriteria yang mumpuni Selain itu, manfaatkan teknologi untuk melakukan otomasi dalam berbagai aktivitas bisnis.

- Mampu beradaptasi dalam berbagai kondisi

Seorang pelaku bisnis UMKM yang sukses, memiliki kemampuan untuk beradaptasi dalam berbagai situasi. Apalagi, di era modern seperti sekarang, perubahan kondisi pasar bisa terjadi secara tiba-tiba. Kalau tak bisa beradaptasi mengikuti perubahan kondisi tersebut, bisa dipastikan usaha Anda bakal kolaps. Kegagalan dalam beradaptasi dengan situasi pasar yang berujung kebangkrutan ini sejatinya menjadi mimpi buruk tak hanya bagi pelaku UMKM, tapi juga pebisnis besar.

- Investasi pada diri sendiri

Melakukan investasi pada diri sendiri jadi hal yang wajib Anda lakukan agar usaha bisa berkembang jadi besar. Investasi bisa dilakukan dalam berbagai cara, termasuk di antaranya adalah dengan melakukan akuisisi. Hanya saja, akuisisi dilakukan dengan mempertimbangkan bujet serta manfaat yang diperoleh. Itulah 5 strategi bisnis yang bisa diterapkan oleh para pelaku UMKM yang ingin mengembangkan usahanya sehingga bisa bersaing dengan pasar internasional. Dengan begitu, tak menutup kemungkinan kalau usaha kecil yang saat ini tengah Anda jalankan, bakal menjadi perusahaan sebesar di beberapa tahun mendatang.

\section{Standarisasi Dan Sertifikasi Adalah Menjamin Dalam Pengembalian Modal Atau Investasi Serta Sebagai Aset Umkm.}

Standarisasi Dan Sertifikasi,juga memberi bisa kemudahan dalam pengembangan usaha antara lain melalui waralaba dan lisensi. "Terkait mutu produk, sistem kekayaan intelektual melindungi konsumen terhindar dari produkproduk palsu yang kualitasnya cenderung rendah", standarisasi dan sertifikasi produk itu harus detail dan spesifik dan harus sesuai dengan standar global. "Standarisasi adalah upaya untuk menjaga kualitas produk dan efisiensi usaha. Sementara sertifikasi merupakan kegiatan penilaian kesesuaian yang berkaitan dengan pemberian jaminan tertulis dan produk telah memenuhi regulasi", produk UMKM Indonesia belum banyak masuk ke rantai pasar global. Pasalnya, produk UMKM Indonesia masih memiliki spek yang rendah dan belum memenuhi standar 
global. "Saat ini, baru sekitar 1,2 juta UMKM yang memiliki hak merek, 49 ribu UMKM yang memiliki hak paten. Jadi, jangan heran bila Kopi Toraja sudah dipatenkan di Jepang",Contohkan produk UMKM komponen, dimana ukuran produk masih beda dan belum memenuhi standar global. "Begitu juga dengan produk handicraft, apakah misalnya produk piring atau gelas hasil kita itu tidak pecah ketika masuk ke microwafe. Intinya, apakah produk UMKM itu sudah berstandar global",

Dengan standarisasi dan sertifikasi produk UMKM, konsumen juga terlindungi. Bisnis makanan dan minuman olahan, harus memperhatikan proses produksinya dengan tetap menjaga higienis dapurnya. Teredapat fakta produk mamin UMKM yang disukai orang-orang di Kanada. Lalu, importir mereka datang melihat proses produksinya kemudian membatalkan. Alasannya, dapur UMKM tersebut dinilai tidak higienis", Hanya ketika produk UMKM memiliki standar ISO dan tersertifikat, juga memiliki konsekuensi yang tidak bisa dihindari. Yaitu, produksi harus konsisten dengan kualitas produk yang tetap terjaga. "Jangan sampai setelah memiliki standar ISO dan sertifikat produk, lalu tidak menjaga kualitas, nama baik produk tersebut akan rusak di pasar", Ada beberapa kegagalan produk UMKM di pasar juga bisa disebabkan karena para UMKM kita sangat bangga dengan hasilnya tanpa memperhatikan kebutuhan dan keinginan konsumen.

Selain itu HAKI pada suatu produk milik UMKM memudahkan UMKM untuk memasuki pasar karena adanya kepastian mengenai kepemilikan dan hak UMKM atas produk atau karyanya. "Persaingan bisnis seringkali tidak mengindahkan etika sehingga menimbulkan pembajakan dan pemalsuan produk", Produk hasil pembajakan tersebut juga bisa muncul karena daya beli masyarakat dimana produk palsu tersebut memiliki harga jual yang lebih rendah dari produk aslinya. "Produk yang sedang ngetren cenderung menjadi korban dari pembajakan atau pemalsuan produk"

Disamping itu untuk memasuki pasar Global pengusaha UMKM harus memahami beberapa prosedur untuk mengekspor produknya kepasar Global, dibawah ini diungkap bagaimana prosedur dan tahap untuk Ekspor:

PROSEDUR EKSPOR

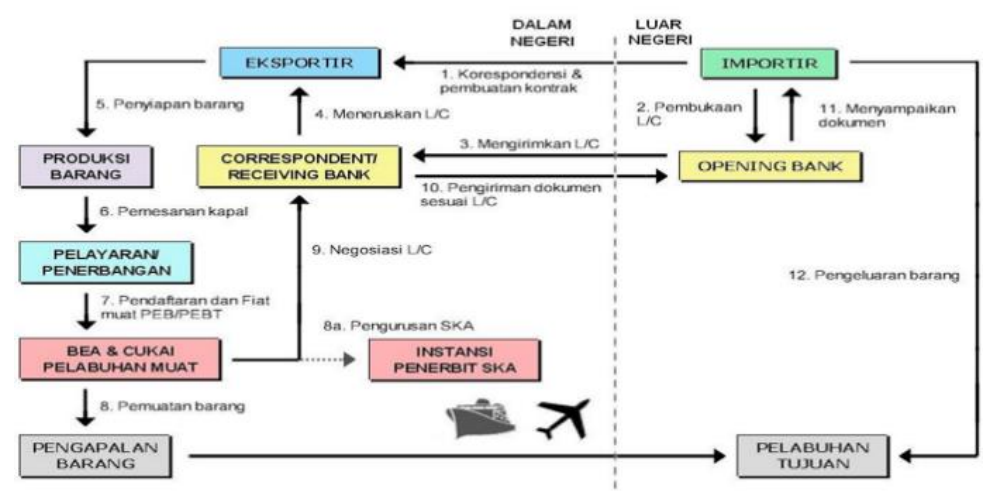

Gambar 2. Tahapan Prosedur Ekspor

Sumber :Dinas Bea Cukai 


\section{Jenis - Jenis Dokumen Ekspor\& Para Pelaku Ekspor}

1. Invoice $=>$ Eksportir

2. Full set on board Ocean Bill of Loading / Airwaybill $=>$ Perusahaan Penerbangan

3. Packing / Weight List $=>$ Eksportir

4. Certificate of Origin $=>$ Kantor Kementerian Perdagangan

5. Insurance Policy $=>$ Perusahaan Asuransi

6. Shipping Agent Certificate $=>$ Perusahaan Agen Pelayaran

7. Exporter's Certificate $=>$ Eksportir

8. Manufacturer's Certificate $=>$ Produsen $/$ Supplier

9. Beneficiary's Certificate $=>$ Eksportir

10. Surveyor's Certificate / Inspection's Certificate $=>$ Independent Surveyor

11. Drafts $=>$ Bank

12. Certificate of Quality $=>$ Balai Pengujian dan Sertifikasi Mutu Barang

13. Manufacturer's Quality Certificate $=>$ Pabrik Pembuat Barang Ekspor

14. Sanitasi Helath And Veterinary Certificate $=>$ Dinas Peternakan

15. Weight Note And Measurement List $=>$ Perusahaan Jasa Transportas

\section{Analisa Karakteristik Budaya Untuk Penetrasi Pasar}

1. Budaya diwariskan secara turun temurun, mencerminkan perilaku belajar yang ditularkan dari satu anggota masyarakat ke anggota masyarakat lainnyaTidak ada salah ataupun benar dalam konteks budaya.Representasi budaya dalam populasi manusia:Estetika, Perilaku dan kepercayaan,Agama,Budaya material,Bahasa, Organisasi sosial, Pendidikan, Karakteristik hukum, Struktur politik

2. Memahami budaya orang lain.Ketika kita berhadapan dengan kebudayan baru, banyak pebisnis internasional membuat kesalahan dengan hanya mengandalkan diri sendiri. Para pebisnis internasional yang sukses bepergian ke luar negeri harus ingat bahwa dia adalah orang asing dan harus berusaha untuk berperilaku dengan aturan budaya di negara tersebut

3. Menghindari culture shock.Contoh pertanyaan yang harus dilontarkan kepada diri pebisnis mengenai budaya terkait negara tujuan untuk membangun suasana yang mendukung proses bisnis yang disesuaikan dengan adat dan kebiasaan

Cross cultural marketing: Memahami norma-norma yang berlaku, Mengetahui dengan pasti pasar sasaran, Mempertimbangkan kendala bahasa, Mengetahui dan memahami nilai-nilai yang dianut.

\section{METODE PELAKSANAAN KEGIATAN}

Metode pelaksanaan PKM dengan pemaparan Edukasi, Forum diskusi dan Tanya Jawab dengan virtual conference menggunakan Zoom Meeting berkaitan dengan Pandemic Covid19. Peserta kegiatan ini adalah para Pengusaha UMKM dan UMKM di Wilayah Kota Bandung, Mahasiswa Pascasarjana Program Magister Manajemen serta Mahasiswa Program Study Manajemen Universitas Widyatama. 


\section{HASIL DAN PEMBAHASAN}

Dengan pemaparan Edukasi, Forum diskusidan Tanya Jawab, tentang Prosedur Ekspor dan tahapnya, Standarisasi Produk untuk Ekspor dan dap Menganalisa Pasar atau Target Pasar Global pada suatu Negara. Diharapkan pasar UMKM dan UMKM ini dapat Termotifasi untuk segera mempersiapkan produk dan bidang usahanya dapat memperluas sasaran dan target pasarnya ke Pasaran Global. Karena Produk-produk UMKM di Indonesia memiliki potensi yang sangat besar untuk menembus pasar ekspor. Dengan melakukan ekspor, UMKM berpotensi untuk mendapatkan keuntungan yang lebih besar, karena pasarnya akan menjadi semakin luas.

Dengan standarisasi dan sertifikasi produk UMKM, konsumen juga terlindungi. Bisnis makanan dan minuman olahan, harus memperhatikan proses produksinya dengan tetap menjaga higienis dapurnya,ketika produk UMKM memiliki standar ISO dan tersertifikat, UMKM juga harus memahami Karakteristik hukum, Struktur politik.dan kebudayaan bangsa atau negara lain, Ketika kita berhadapan dengan kebudayan baru, banyak pembisnis internasional tidak lagi membuat kesalahan berusaha untuk berperilaku dengan aturan budaya di negara tersebut, sehingga dapat Menghindari culture shock dan lebih memahami Cross cultural marketing.

\section{KESIMPULAN DAN SARAN}

Dapat disimpulkan, bahwa dengan memahami prosedur ekspor dan tahapnya, standarisasi produk untuk ekspor dan dapat menganalisa pasar atau targer pasar global pada suatu Negara, dengan adanya kegiatan PKM ini dengan pemaparan edukasi tentang Analisa perkembangan pasar global, prosedur ekspor, mekanisme yang harus dilalui supaya produknya bisa dieskpor ke luar negeri serta pemahaman kebudayaan negara lain yang menjadi target pasar UMKM, yang memiliki cita-cita untuk mengembangkan usahanya sampai ke pasar luar negeri atau pasar global dapat terwujudkan.

Saran untuk UMKM, harus memahami dan mempelajari dan mencari informasi semua prosedur terkait produk yang akan di ekspor, melaksanakan apa yang menjadi ketentuan syarat ekspor dan standarisasinya, dan dapat menganalisa pasar global dan karekteristik masyarakat pasar global tersebut. Selain itu para pelaku UMKM harus lebih sering berkomunikasi dan menjalin hubungan baik dengan instansi terkait, seperti pihak pembina UMKM, lembaga legalitas dan pemerintahan terkait, serta menjalin hubungan baik denga para pelaku UMKM lainnya, agar dapat sharing pengalaman dan ilmunya.

\section{DAFTAR PUSTAKA}

Alan dkk. 2014. Center of Indonesian Sharia Investment (CISI) Sebagai

Amir MS, Pengetahuan Bisnis Ekspor Impor Seri Umum No 8, PT. Pustaka

Binaman Pressindo, Jakarta, 2009. 
Departemen Perdagangan RI, Buku Panduan Peraturan dan Prosedur Ekspor Indonesia, Departemen Perdagangan RI bekerjasama dengan Dewan Penunjang Ekspor, Jakarta, 2005.

DepartemenPerdaganganRepublik Indonesia. Menuju ASEAN Economic Community 2015, E-book. DepartemenPerdaganganRepublik Indonesia

Haque, MG., Munawaroh, Sunarsi, D., (2020). Analysis of SMEs Culinary Marketing Strategy During Covid 19 Pancemic: A Study at "Sate Bebek Cilegon" Resto in Cilegon, Banten. International Journal of Education, Information Technology, and Others. Vol.3. Issue 2

KementerianPerdaganganRepublik Indonesia. Menuju ASEAN Economic Community 2015.

Letter Of Credit :Dalam Bisnis Ekspor Impor, Seri ke9, PPM, Jakarta, 2011.

Lukiastuti, Fitri, et.al (2020). The Influence of Entrepreneur's Personal Characteristics on SMES Performance Mediated by Entrepreneurial Orientation. International Journal of Psychosocial Rehabilitation. Volume 24 - Issue 8

Maddinsyah, A., Sunarsi, D., Hermawati, R., Pranoto. (2020). Analysis of location selection effect on the user decision that influcence the success of the service business of micro, small and medium enterprise (MSME) in bandung timur region. International Journal of Advanced Science and Technology. Vol. 29 No. 06

Seluk Beluk dan Teknik Perdagangan Luar Negeri, Seri BisnisInternasional No 4 PPM, Jakarta, 2000.

Suroyo, Arif, danHarmanti, KepabeanandanCukai, Universitas Terbuka, Jakarta,2009.

Sutarto, Eddhi, RekonstruksiSistemHukumPabean Indonesia, Erlangga, Jakarta, 2010.

Upaya Peningkatan dan Penguatan Perekonomian Indonesia Dalam Arus Bebas Investasi AEC 2015, karya tulis ilmiah FEB Undip. Semarang: FEB. 